\title{
In situ thermally reduced graphene oxide/epoxy composites: thermal and mechanical properties
}

\author{
Ganiu B. Olowojoba ${ }^{1} \cdot$ Salvador Eslava $^{2,3} \cdot$ Eduardo S. Gutierrez $^{2}$ • \\ Anthony J. Kinloch ${ }^{1} \cdot$ Cecilia Mattevi $^{2}$ Victoria G. Rocha ${ }^{2} \cdot$ Ambrose C. Taylor $^{1}$
}

Received: 23 September 2015/Accepted: 5 January 2016/Published online: 30 January 2016

(c) The Author(s) 2016. This article is published with open access at Springerlink.com

\begin{abstract}
Graphene has excellent mechanical, thermal, optical and electrical properties and this has made it a prime target for use as a filler material in the development of multifunctional polymeric composites. However, several challenges need to be overcome to take full advantage of the aforementioned properties of graphene. These include achieving good dispersion and interfacial properties between the graphene filler and the polymeric matrix. In the present work, we report the thermal and mechanical properties of reduced graphene oxide/epoxy composites prepared via a facile, scalable and commercially viable method. Electron micrographs of the composites demonstrate that the reduced graphene oxide ( $\mathrm{rGO})$ is well dispersed throughout the composite. Although no improvements in glass transition temperature, tensile strength and thermal stability in air of the composites were observed, good improvements in thermal conductivity (about $36 \%$ ), tensile and storage moduli (more than $13 \%$ ) were recorded with the addition of $2 \mathrm{wt} \%$ of $\mathrm{rGO}$.
\end{abstract}

Keywords Thermal reduction - Graphene oxide · Reduced graphene oxide · Tensile modulus - Thermal conductivity · Glass transition temperature - Dispersion . In situ processing

Ganiu B. Olowojoba

g.olowojoba@imperial.ac.uk

1 Mechanics of Materials Division, Department of Mechanical Engineering, Imperial College London, London, UK

2 Centre for Advanced Structural Ceramics, Department of Materials, Imperial College London, London, UK

3 Department of Chemical Engineering, University of Bath, Bath, UK

\section{Introduction}

Due to its remarkable mechanical, electrical and thermal properties, graphene has evoked a lot of interest amongst researchers working on the development of multi-functional composites for a variety of applications (Potts et al. 2011; Geim and Novoselov 2007; Balandin et al. 2008; Yu et al. 2007; Liang et al. 2009; Kim and Macosko 2009). However, the inert nature of graphene makes it difficult to take full advantage of its excellent properties when used as a filler material in polymeric composites. Such composites are usually characterized by poor filler dispersion and poor interfacial properties between the filler and the polymeric matrix material, arising from the poor compatibility between graphene and many polymeric matrices. Functionalization of the graphene has been widely adopted as one of the ways of overcoming the aforementioned challenges, either by allowing the easy exfoliation of graphite platelets or increasing the compatibility between graphene sheets and the chosen polymeric matrix (Kuilla et al. 2010; Pei and Cheng 2012). Oxidized graphene sheets, known as graphene oxide (GO) sheets, are typically prepared by oxidation and exfoliation of graphite (Hummers and Offeman 1958; Marcano et al. 2010) and have been used as the starting material in the production of graphene-based composites. Although some researchers have reduced GO in situ using hazardous chemical reagents such as hydrazine hydrate (Yousefi et al. 2013), others prefer to reduce GO prior to its incorporation in composites (Liang et al. 2009; Potts et al. 2011).

In the present work, reduced graphene oxide ( $\mathrm{rGO}) /$ epoxy composites are produced in a facile, scalable and commercially viable way. This involves dispersing freezedried GO in a diglycidyl ether of bisphenol-A (DGEBA) epoxy resin by shear mixing. The GO is then reduced 
in situ (to rGO) using a relatively high-temperature cure schedule for the epoxy resin system, after adding the hardener. The thermal and mechanical properties of the composites produced are characterized and the viability of the processing technique is demonstrated. The advantages of this processing route when compared to those adopted by others are: (1) it does not involve the use of solvents or hazardous GO reducing agents such as hydrazine hydrate; and (2) in situ reduction of the GO during the curing of the epoxy eliminates the extra step in the production process of having to reduce the GO prior to incorporation in the matrix.

\section{Experimental}

\section{Materials}

A standard DGEBA resin (Araldite LY556; Huntsman, UK), having an epoxide equivalent weight (EEW) of $185 \mathrm{~g} / \mathrm{eq}$, was used. The curing agent was an accelerated methylhexahydrophthalic acid anhydride (Albidur HE600; Evonik, Germany), having an anhydride equivalent weight $(\mathrm{AEW})$ of $170 \mathrm{~g} / \mathrm{eq}$.

\section{Graphene oxide synthesis}

A suspension of graphene oxide was prepared via a modified Tour et al. (Marcano et al. 2010) synthesis in a custom-built rig, using natural graphite flakes (150-500 $\mu \mathrm{m}$, Sigma-Aldrich). This was freeze-dried using a Powerdry LL1500 freeze dryer (Thermo Scientific, UK).

\section{Composite preparation}

The freeze-dried GO, having an average lateral size of $33 \pm 17 \mu \mathrm{m}$, was dispersed in the DGEBA epoxy resin using a three-roll mill (80E; Exakt, Germany) as described elsewhere (Olowojoba et al. 2013). A stoichiometric amount of the anhydride (Albidur HE600) was then added to the GO/DGEBA mixture (i.e. the ratio of DGEBA to anhydride was kept at $185: 170$, according to their equivalent weights). The resulting mixture was stirred at $500 \mathrm{rpm}$ for $15 \mathrm{~min}$ at a temperature of $60{ }^{\circ} \mathrm{C}$ under atmospheric pressure using an overhead stirrer. The mixture was degassed at $-1000 \mathrm{mbar}$ and $60{ }^{\circ} \mathrm{C}$ for $15 \mathrm{~min}$ to remove trapped air bubbles. The degassed mixture was poured into preheated rectangular steel moulds with internal dimensions of $150 \times 80 \times 3 \mathrm{~mm}^{3}$ and cured at $90{ }^{\circ} \mathrm{C}$ for $1 \mathrm{~h}$, and $160{ }^{\circ} \mathrm{C}$ for $2 \mathrm{~h}$. A post-cure step of $200{ }^{\circ} \mathrm{C}$ for $30 \mathrm{~min}$ was carried out to ensure sufficient in situ thermal reduction of the GO, to rGO, in the composite (Tang et al. 2012).

\section{Thermogravimetric analysis}

Thermogravimetric analysis (TGA) was carried out on the composites and GO samples using a TGA/DSC 1 apparatus (Mettler Toledo, UK). A sample of the freeze-dried GO was thermally reduced according to the cure schedule employed for processing the composites (i.e. $90{ }^{\circ} \mathrm{C}$ for $1 \mathrm{~h}$; $160{ }^{\circ} \mathrm{C}$ for $2 \mathrm{~h}$ and $200{ }^{\circ} \mathrm{C}$ for $30 \mathrm{~min}$ ). To investigate the thermally induced dissociation of the GO and rGO, samples were analysed in a nitrogen atmosphere using a heating rate of $5{ }^{\circ} \mathrm{C} / \mathrm{min}$. Thermal oxidation of the composites, on the other hand, was analysed in air using a heating rate of $10^{\circ} \mathrm{C} / \mathrm{min}$. All samples were analysed over the temperature range $30-800{ }^{\circ} \mathrm{C}$.

\section{Dynamic mechanical thermal analysis}

The thermo-mechanical properties of the rGO/epoxy composites were determined using a Q800 dynamic mechanical thermal analyser (DMTA) from TA Instruments, UK. Rectangular samples with dimensions $60 \times 10 \times 3 \mathrm{~mm}^{3}$ were subjected to temperature sweeps from 30 to $200{ }^{\circ} \mathrm{C}$ at a heating rate of $2{ }^{\circ} \mathrm{C} / \mathrm{min}$ in a dualcantilever mode using a frequency of $1 \mathrm{~Hz}$ and an oscillation strain of $0.05 \%$. The number average molecular weight, $M_{\mathrm{nc}}$, between cross-links was calculated from Eq. (1):

$M_{\mathrm{nc}}=\frac{q \rho R T}{E_{\mathrm{r}}}$

where $E_{\mathrm{r}}$ is the rubbery storage modulus determined at the temperature, $T$, of $453 \mathrm{~K}\left(180{ }^{\circ} \mathrm{C}\right), R$ is the universal gas constant $\left(8.314 \mathrm{~cm}^{3} \mathrm{MPa} / \mathrm{K} \mathrm{mol}\right)$ and $\rho$ is the density of the epoxy determined at room temperature $\left[1.2 \mathrm{~g} / \mathrm{cm}^{3}\right.$ (Chen et al. 2013)]. Since the density of the epoxy was determined at room temperature, Pearson and Yee (1989) suggest a front factor, $q$, of 0.725 .

\section{X-ray photoelectron spectroscopy}

X-ray photoelectron spectroscopy (XPS) analyses were performed using a Theta Probe spectrometer (ThermoFisher Scientific; UK). The instrument was operated at a base pressure of $1 \times 10^{-9}$ mbar. XPS spectra were acquired using an MXR1 monochromated $\mathrm{Al} \mathrm{K} \alpha \mathrm{X}$-ray source $(h v=1486.6 \mathrm{eV})$. An X-ray spot of $\sim 400 \mu \mathrm{m}$ radius was employed. High-resolution, core level $\mathrm{C} 1 \mathrm{~s}$ spectra were acquired using a pass energy of $20 \mathrm{eV}$. The GO sample spectra were charge referenced against the $\mathrm{C} 1 \mathrm{~s}$ peak at $284.4 \mathrm{eV}$ to correct for charging effects during acquisition. 


\section{Tensile test}

Uniaxial tensile tests were conducted on the rGO/epoxy composites at room temperature using a universal tensile testing machine (5584; Instron, UK). Dumbbell specimens having a gauge length of $25 \mathrm{~mm}$ were used. A displacement rate of $1 \mathrm{~mm} / \mathrm{min}$ was adopted. The tensile properties were averaged from the results obtained from a minimum of five specimens. The strain was measured using a clip-on extensometer.

\section{Thermal conductivity measurement}

The thermal conductivities of the rGO/epoxy composites were determined from their thermal diffusivities measured by the laser-flash technique using an LFA-427 Nanoflash (Netzsch, Germany). Three shots each were made on $10 \times 10 \mathrm{~mm}^{2}$ samples which were $2 \mathrm{~mm}$ thick. A temperature range of $30-60{ }^{\circ} \mathrm{C}$ was used, at $10{ }^{\circ} \mathrm{C}$ intervals, with a laser voltage of $450 \mathrm{~V}$ and a pulse width of $0.8 \mathrm{~ms}$. The samples were coated with a thin layer of graphite prior to testing to increase absorption and transmission of the infrared radiation energy.

\section{Scanning electron microscopy}

The morphology of the fracture surfaces of the composites was examined using a Leo 1525 (Carl Zeiss, Germany) scanning electron microscope equipped with a field emission gun (FEG-SEM). An accelerating voltage of $5 \mathrm{kV}$ was used, with the samples being sputter-coated with a thin layer of chromium prior to examination.

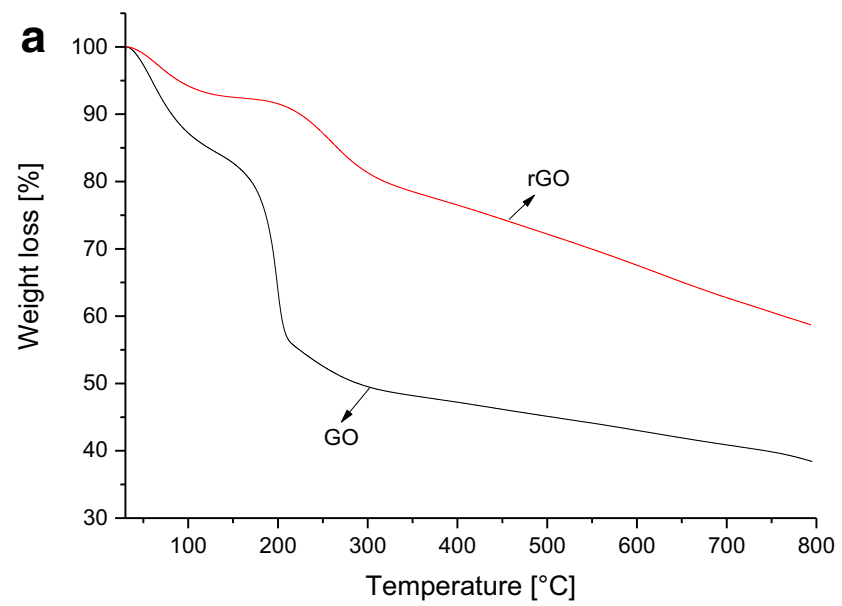

\section{Results and discussion}

\section{Reduction of graphene oxide}

Figure 1a shows the thermograms of the pristine GO and of the rGO reduced according to the temperature schedule adopted for curing the composites. In both thermograms, the weight loss at $100{ }^{\circ} \mathrm{C}$, of $15 \%$ in the case of GO and $7 \%$ in the case of rGO, may be attributed to the evaporation of adsorbed water. A further $30 \%$ weight loss at $200{ }^{\circ} \mathrm{C}$ can be observed in the case of GO. This has been attributed to the thermal decomposition of oxygen-containing functional groups (OCFGs) on the surface of the GO. It has previously been shown that most of the OCFGs, which are attached to the basal aromatic plane of a GO sheet (i.e. hydroxyl and epoxy groups), can be removed by annealing at $200{ }^{\circ} \mathrm{C}$ (Tang et al. 2012; Jeong et al. 2009), thus partially restoring the thermal, electrical and optical properties of graphene. The OCFGs which are attached to the edges of the GO sheets are however more thermally stable and will only decompose at temperatures higher than $200{ }^{\circ} \mathrm{C}$, as illustrated by the weight loss between 200 and $800{ }^{\circ} \mathrm{C}$. (Pei and Cheng 2012).

Figure 1b shows the C1s XPS spectra of GO and rGO, as well as the associated four-component fit which quantitatively represents the bonds between the carbon atoms on the GO and other moieties. A significant reduction in the OCFGs bonded to carbon atoms can be observed upon reduction of the $\mathrm{GO}$ to $\mathrm{rGO}$, in agreement with the TGA results discussed above. These techniques clearly demonstrate the effectiveness of the GO reduction strategy adopted in this work for the preparation of the $\mathrm{rGO} /$ epoxy composites.

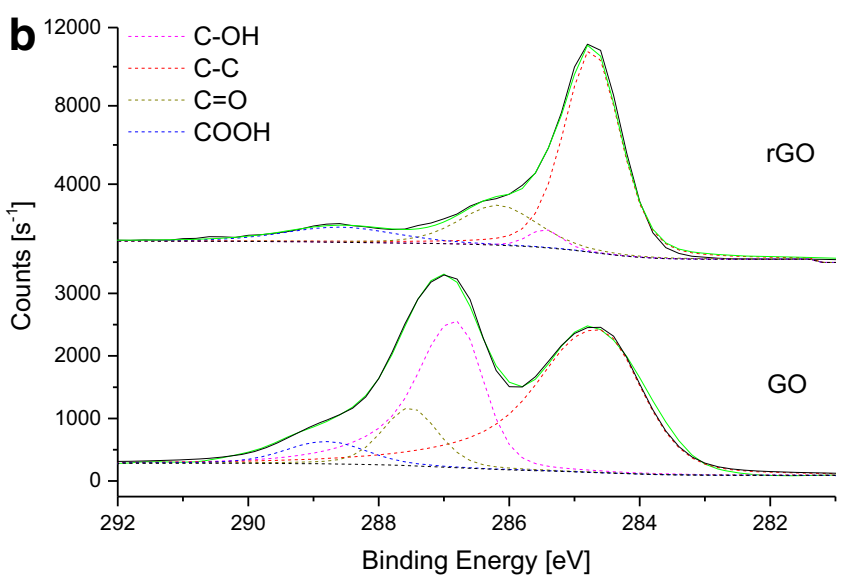

Fig. 1 a Thermograms of GO and rGO in a nitrogen atmosphere with a heating rate of $5{ }^{\circ} \mathrm{C} / \mathrm{min}$; $\mathbf{b}$ XPS of GO before and after reduction showing a decrease in the concentrations of functional groups present after reduction of GO to rGO 


\section{Morphologies of the rGO/epoxy composites}

The morphologies of the fracture surfaces of the composites are shown in Fig. 2. Although the surface morphology of the neat epoxy (Fig. 2a) appears relatively smooth with river lines characteristic of a brittle fracture, those of the composites (Fig. 2b-e) exhibit increasing surface roughness with increasing rGO content.

It can also be seen in Fig. 2b-e that the rGO appears to be evenly dispersed throughout the composite. This is to be expected due to the fact that the GO contains epoxy groups which would impart good compatibility with the DGEBA resin and improve dispersion during mixing. Furthermore, since significant reduction of the GO takes place at $200{ }^{\circ} \mathrm{C}$, the epoxy matrix would have already gelled at this temperature, therefore preventing re-agglomeration of any unattached $\mathrm{rGO}$ during reduction.

\section{Thermo-mechanical properties}

The thermo-mechanical properties of the in situ thermally reduced rGO/epoxy composites are shown in Fig. 3.
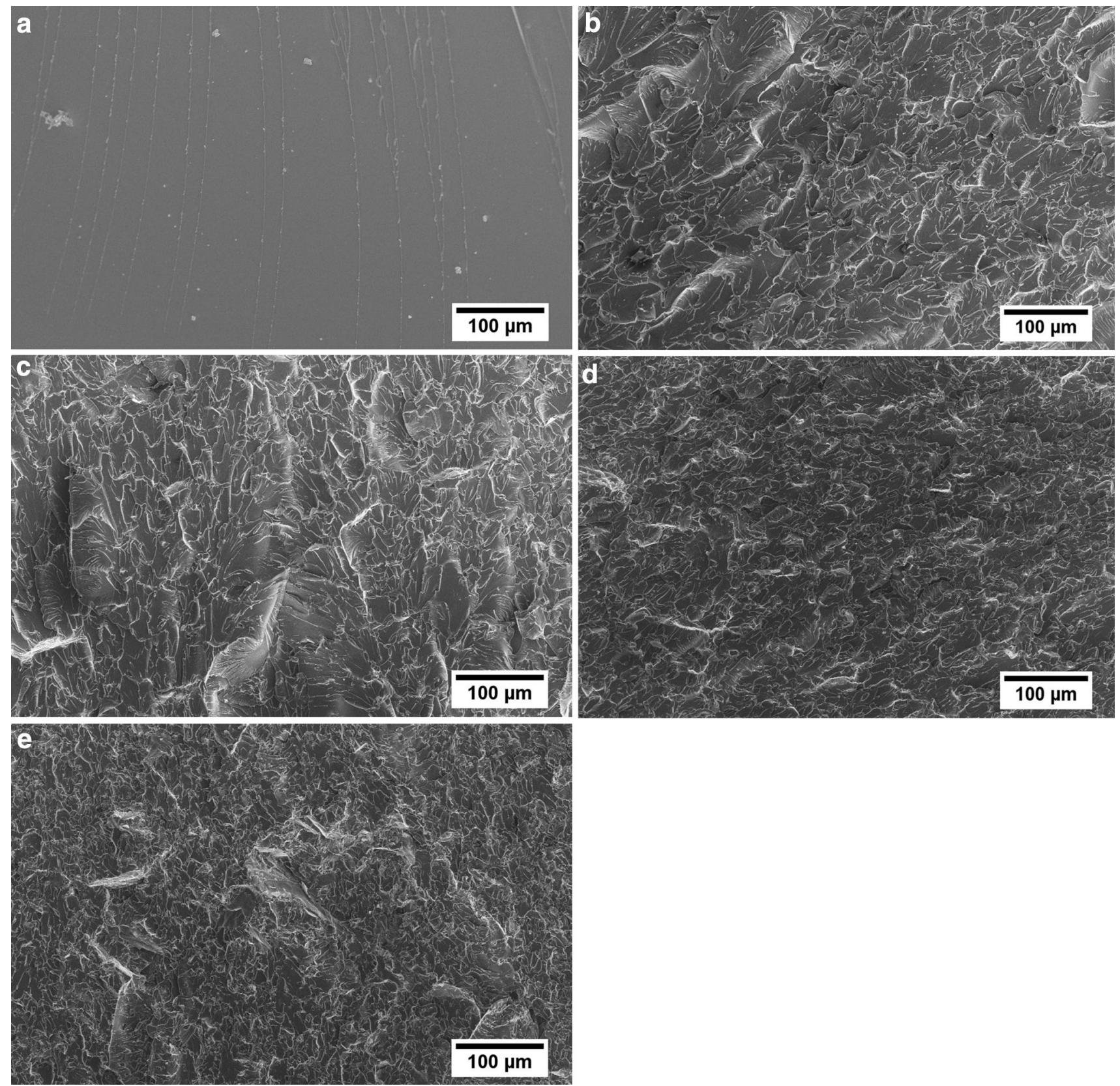

Fig. 2 Fracture surface morphology of rGO/epoxy composites examined using FEG-SEM. a Neat epoxy, b 0.1 wt $\%$, c 0.5 wt $\%$, d 1 wt $\%$, e $2 \mathrm{wt} \% \mathrm{rGO}$ 

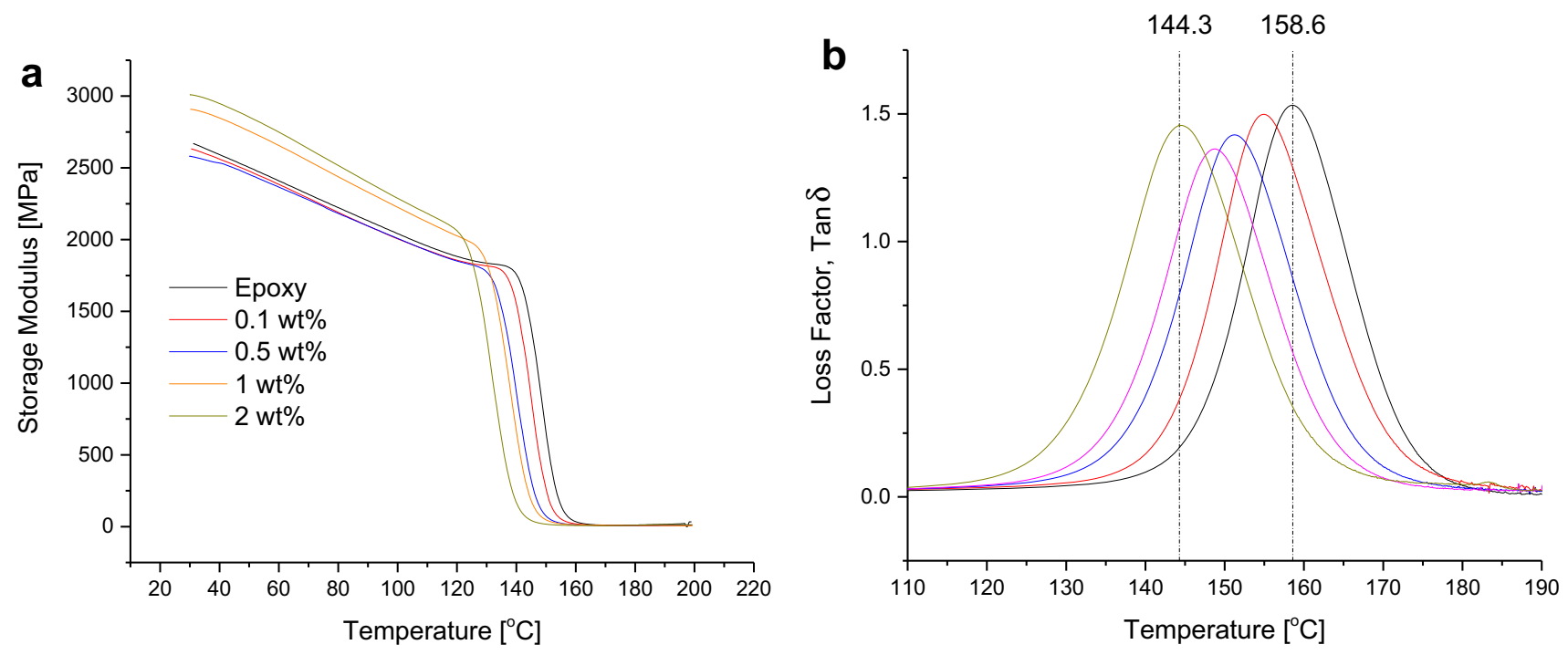

Fig. 3 Thermo-mechanical properties of the rGO/epoxy composites

Table 1 Thermo-mechanical properties of the rGO/epoxy composites

\begin{tabular}{lllll}
\hline $\begin{array}{l}\text { rGO content } \\
(\mathrm{wt} \%)\end{array}$ & $\begin{array}{l}\text { Storage modulus, } E_{\mathrm{g}} \text {, at } \\
35{ }^{\circ} \mathrm{C}(\mathrm{MPa})\end{array}$ & $\begin{array}{l}\text { Storage modulus, } E_{\mathrm{r}}, \text { at } \\
180{ }^{\circ} \mathrm{C}(\mathrm{MPa})\end{array}$ & $\begin{array}{l}\text { Average molecular weight between } \\
\text { cross-links, } M_{\mathrm{nc}}(\mathrm{g} / \mathrm{mol})\end{array}$ & $\begin{array}{l}\text { Glass transition } \\
\text { temperature, } T_{\mathrm{g}}\left({ }^{\circ} \mathrm{C}\right)\end{array}$ \\
\hline 0.0 & 2640 & 11.5 & 285 & 158.6 \\
0.1 & 2690 & 10.2 & 321 & 154.8 \\
0.5 & 2758 & 8.4 & 390 & 151.2 \\
1.0 & 2891 & 6.1 & 537 & 148.8 \\
2.0 & 2990 & 4.5 & 728 & 144.3 \\
\hline
\end{tabular}

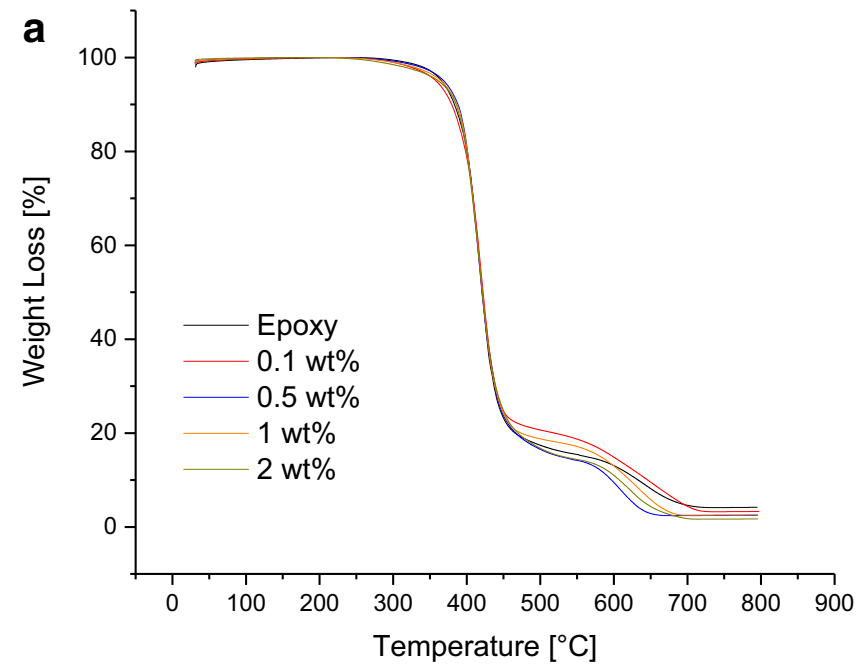

Fig. 4 Thermogravimetric analysis of the rGO/epoxy composites

From Fig. 3a, the glassy storage moduli, $E_{\mathrm{g}}$, of the composites, measured at $35{ }^{\circ} \mathrm{C}$, can be seen to increase with increasing rGO content; rising from $2640 \mathrm{MPa}$ for the

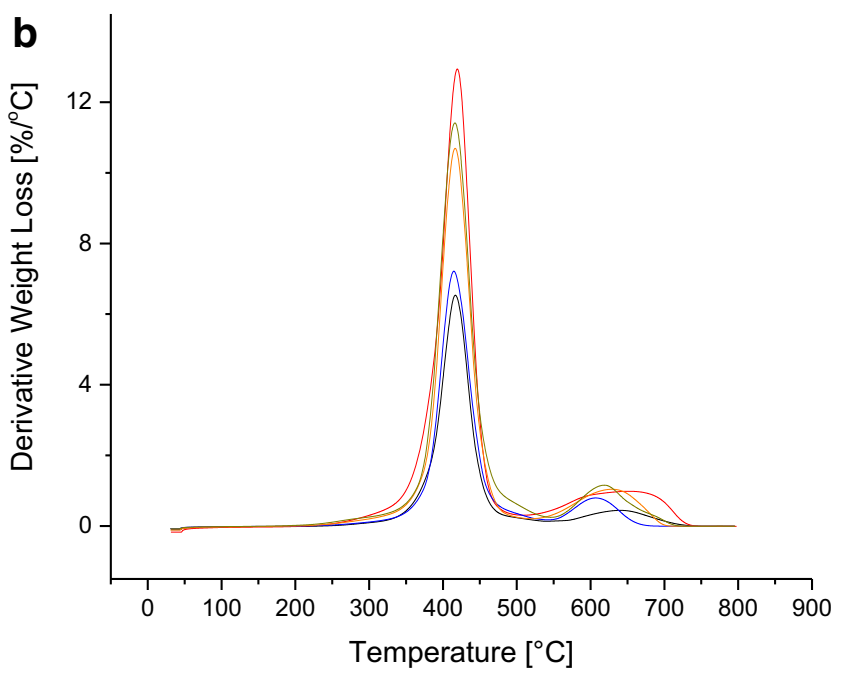

neat epoxy polymer to $2990 \mathrm{MPa}$ in the epoxy composite filled with 2 wt\% rGO (see Table 1). The values of the glass transition temperature, $T_{\mathrm{g}}$, of the epoxy matrices, 
which has been taken as the maximum of the $\tan \delta$ curve (Fig. 3b), were however observed to decrease with increasing $\mathrm{rGO}$ content from $158.6{ }^{\circ} \mathrm{C}$ for the neat epoxy to $144.3{ }^{\circ} \mathrm{C}$ for the composite with $2 \mathrm{wt} \%$ rGO (i.e. a decrease of nearly $15{ }^{\circ} \mathrm{C}$ ). As discussed elsewhere (Yang et al. 2009), the increase in the storage modulus may be attributed to good interfacial adhesion between the rGO and the epoxy matrix due to the chemical interaction between the functional groups on the GO and epoxy during the in situ reduction. This chemical interaction between the GO and epoxy may also lead to an increase in the molecular weight between cross-links of the cured epoxy matrix (Zaman et al. 2011; Ma et al. 2013; Yousefi et al. 2013) as the rGO content is increased. The number average molecular weight between cross-links, $M_{\mathrm{nc}}$, are listed in Table 1 . The storage moduli, $E_{\mathrm{r}}$, in the rubbery region (at $180^{\circ} \mathrm{C}$ ), from which the $M_{\mathrm{nc}}$ were calculated according to Eq. (1), are also listed in Table 1. $M_{\mathrm{nc}}$ increases from $285 \mathrm{~g} / \mathrm{mol}$ in the neat epoxy to $728 \mathrm{~g} / \mathrm{mol}$ in the composite filled with 2 wt $\%$ rGO. Chen et al. (2013) obtained a similar value of $M_{\mathrm{nc}}$ for the neat epoxy. The reaction between pendant OCFGs on the GO surface and the epoxy matrix in the liquid phase is well known. Yang et al. (2009) has shown that DGEBA molecules can indeed be grafted onto GO by reaction with pendant OCFGs in an aqueous medium if a mixture of $\mathrm{GO}$ and resin is heated at $50{ }^{\circ} \mathrm{C}$ while stirring for $4 \mathrm{~h}$. Wan et al. (2014) prepared DGEBAfunctionalized GO sheets by dispersing GO sheets in acetone via bath sonication in the presence of DGEBA resin at $70{ }^{\circ} \mathrm{C}$ using $\mathrm{NaOH}$ as catalyst. They confirmed grafting of DGEBA onto the GO sheets using a combination of XPS, $\mathrm{XRD}$, atomic force microscopy (AFM), transmission electron microscopy (TEM) and Raman spectroscopy. The degassing step adopted in this work for the removal of trapped air (i.e. using $60{ }^{\circ} \mathrm{C},-1000 \mathrm{mbar}$ and time of $15 \mathrm{~min}$ ) may also encourage the reaction of the OCFGs on

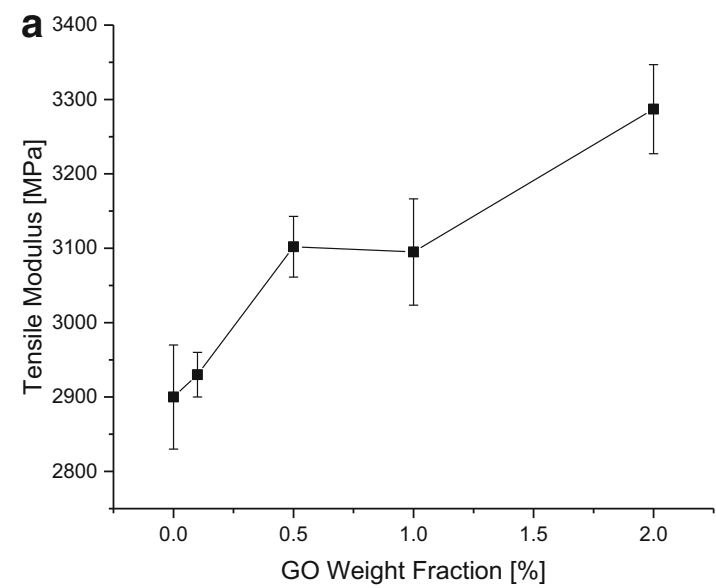

the GO with the functional groups on the DGEBA resin. For these reasons, the $M_{\mathrm{nc}}$ increases and the glass transition temperature decreases, as the rGO concentration increases. Addition of GO has also been reported to change the molecular weight of polyurethane (Kim et al. 2010). Nanoclays are also known to have a similar effect on epoxy polymers (Liu et al. 2005; Marouf et al. 2008).

\section{Thermal stability in air}

Figure 4 shows the thermal stability of the rGO/epoxy composites in air as measured using TGA. The thermal stabilities of the composites appear to decrease somewhat with increasing rGO content. This can be seen more clearly in Fig. $4 \mathrm{~b}$ where the rate of thermal degradation of the composites at around $400{ }^{\circ} \mathrm{C}$ increases with increasing rGO content. Since the GO is only partially reduced in the composite, the oxygen content of the cured composite may therefore be expected to increase with increasing rGO content. This will lead to an increase in the rate of thermal degradation, as confirmed in Fig. 4b.

\section{Tensile properties}

Figure 5a shows the tensile moduli of the composites. The moduli increase from $2900 \pm 70 \mathrm{MPa}$ for the neat epoxy to $3290 \pm 60 \mathrm{MPa}$ for the $2 \mathrm{wt} \% \mathrm{rGO} /$ epoxy composite (i.e. an increase of $13.4 \%$ ). Tschoppe et al. (2015) report an increase in the modulus of $8.5 \%$ for an epoxy composite filled with $1.5 \mathrm{wt} \%$ of thermally reduced GO and $11.4 \%$ for that filled with $2 \mathrm{wt} \%$ of nitrogen-doped thermally reduced GO, whereas Zaman et al. (2011) observed a modest $7 \%$ increase in modulus on adding 2 wt $\%$ of 4,4'methylene diphenyl diisocyanate (MDI)-functionalized GNP to epoxy. The increase in modulus observed in the present work may be ascribed to the relatively high

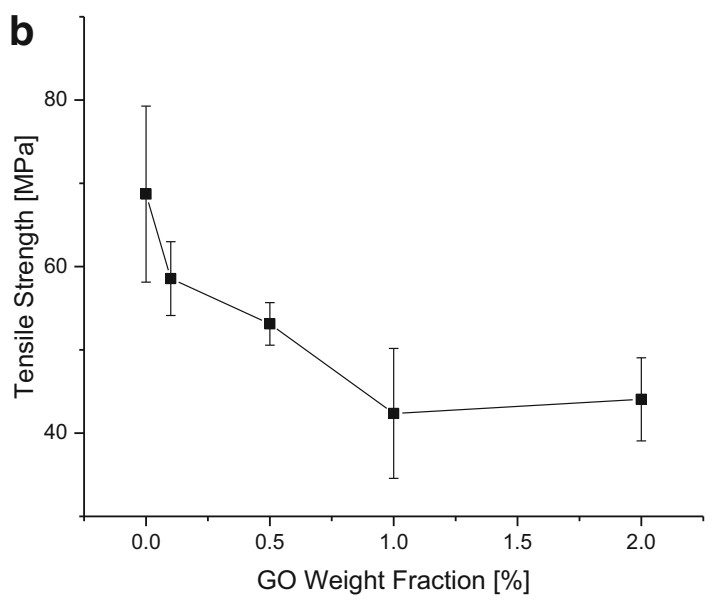

Fig. 5 Mechanical properties of the rGO/epoxy composites: a Young's modulus, b tensile strength 


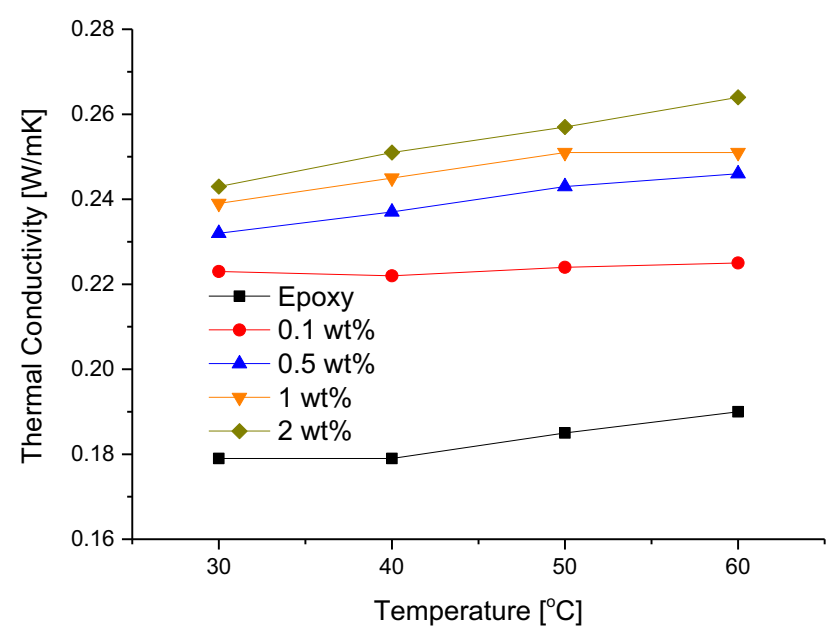

Fig. 6 Thermal conductivities of neat epoxy and rGO/epoxy composites at different temperatures

modulus of the rGO filler and to the good interfacial adhesion between the rGO and the epoxy matrix. Good interfacial adhesion may arise from surface chemistry interactions, as well as from mechanical interlocking of the wavy rGO sheets with the epoxy matrix (Yang et al. 2009). As Fig. 5b shows, the tensile strengths of the composites tend to decrease with increasing rGO content. The tensile strength decreases from $68.7 \pm 10.6 \mathrm{MPa}$ in the neat epoxy to $44.1 \pm 5.0 \mathrm{MPa}$ in the composite with $2 \mathrm{wt} \%$ rGO. Such a decrease has been attributed to defects as well as to the change in molecular weight between cross-links of the epoxy matrix, as mentioned above. Zaman et al. (2011) obtained similar results with MDI-functionalized graphene nanoplatelet (GNP)/epoxy composites.

\section{Thermal conductivity}

Figure 6 shows the thermal conductivities of the rGO/ epoxy composites. The thermal conductivities tend to increase with increasing rGO content and also with increasing temperature, as expected. The maximum thermal conductivity recorded was $0.264 \mathrm{~W} / \mathrm{mK}$ for the $2 \mathrm{wt} \%$ rGO/epoxy composite at $60{ }^{\circ} \mathrm{C}$. The corresponding thermal conductivity of the neat epoxy polymer is $0.190 \mathrm{~W} / \mathrm{mK}$. At $30{ }^{\circ} \mathrm{C}$, the corresponding values are $0.243 \mathrm{~W} / \mathrm{mK}$ and $0.179 \mathrm{~W} / \mathrm{mK}$ for the $2 \mathrm{wt} \% \mathrm{rGO} / \mathrm{epoxy}$ composite and neat epoxy, respectively (i.e. an increase of about $36 \%$ ). The measured thermal conductivities exhibited by these composites are relatively high when compared to the value of $0.21 \mathrm{~W} / \mathrm{mK}$ reported in the literature for a GNP/epoxy composite (Chandrasekaran et al. 2013). This may be attributed to the excellent dispersion of the rGO in the epoxy resulting from the processing technique adopted in the present work.

\section{Conclusions}

A facile, scalable and commercially viable method has been developed to prepare polymeric composites of a DGEBA epoxy resin with varying rGO content, having improved thermal conductivities. It consists of dispersing freeze-dried GO in a DGEBA epoxy resin using a three-roll mill and subsequently curing at a relatively high temperature with an anhydride curing agent, thereby both partially reducing the GO to rGO in situ and curing the epoxy matrix. The rGO/epoxy composites so produced exhibit a good dispersion of rGO, as observed by electron microscopy, which ensures significant improvements in the thermal conductivity, storage modulus and tensile modulus. Other properties are however slightly reduced, such as the thermal stability, glass transition temperature and tensile strength, probably due to oxygen groups remaining on the embedded rGO and an increase in the molecular weight between cross-links for the epoxy matrices. These results show that it is possible to tune the properties of an epoxy polymer with a simple and viable method of GO addition.

Acknowledgments This work was funded by the UK Engineering and Physical Sciences Research Council (EPSRC), Grant Number: $\mathrm{EP} / \mathrm{K} 016792 / 1$. The authors wish to thank the Department of Mechanical Engineering Sciences, University of Surrey, UK, for the X-ray photoelectron spectroscopy measurements. V. G. Rocha would like to acknowledge the European Commission (FP7 Marie Curie Intra-European Fellowships GRAPES).

Open Access This article is distributed under the terms of the Creative Commons Attribution 4.0 International License (http:// creativecommons.org/licenses/by/4.0/), which permits unrestricted use, distribution, and reproduction in any medium, provided you give appropriate credit to the original author(s) and the source, provide a link to the Creative Commons license, and indicate if changes were made.

\section{References}

Balandin AA, Ghosh S, Bao W, Calizo I, Teweldebrhan D, Miao F et al (2008) Superior thermal conductivity of single-layer graphene. Nano Lett 8(3):902-907

Chandrasekaran S, Seidel C, Schulte K (2013) Preparation and characterization of graphite nano-platelet (GNP)/epoxy nanocomposite: mechanical, electrical and thermal properties. Eur Polym J 49(12):3878-3888

Chen J, Kinloch AJ, Sprenger S, Taylor AC (2013) The mechanical properties and toughening mechanisms of an epoxy polymer modified with polysiloxane-based core-shell particles. Polymer 54(16):4276-4289

Geim AK, Novoselov KS (2007) The rise of graphene. Nat Mater 6:183-191

Hummers WS, Offeman RE (1958) Preparation of graphitic oxide. J Am Chem Soc 80(6):1339

Jeong H, Lee YP, Jin MH, Kim ES, Bae JJ, Lee YH (2009) Thermal stability of graphite oxide. Chem Phys Lett 470(4-6):255-258 
Kim H, Macosko CW (2009) Processing-property relationships of polycarbonate/graphene composites. Polymer 50(15):3797-3809

Kim H, Miura Y, Macosko CW (2010) Graphene/polyurethane nanocomposites for improved gas barrier and electrical conductivity. Chem Mater 22(11):3441-3450

Kuilla T, Bhadra S, Yao D, Kim NH, Bose S, Lee JH (2010) Recent advances in graphene based polymer composites. Prog Polym Sci 35(11):1350-1375

Liang J, Wang Y, Huang Y, Ma Y, Liu Z, Cai J et al (2009) Electromagnetic interference shielding of graphene/epoxy composites. Carbon 47(3):922-925

Liu W, Hoa SV, Pugh M (2005) Organoclay-modified high performance epoxy nanocomposites. Compos Sci Technol 65(2):307-316

Ma J, Meng Q, Michelmore A, Kawashima N, Izzuddin Z, Bengtsson $C$ et al (2013) Covalently bonded interfaces for polymer/graphene composites. J Mater Chem A 1(13):4255-4264

Marcano DC, Kosynkin DV, Berlin JM, Sinitskii A, Sun Z, Slesarev A et al (2010) Improved synthesis of graphene oxide. ACS Nano 4(8):4806-4814

Marouf BT, Bagheri R, Pearson RA (2008) Observation of two $\alpha$ relaxation peaks in a nanoclay-filled epoxy compound. J Mater Sci 43(21):6992-6997

Olowojoba G, Sathyanarayana S, Caglar B, Kiss-Pataki B, Mikonsaari I, Hübner C et al (2013) Influence of process parameters on the morphology, rheological and dielectric properties of threeroll-milled multiwalled carbon nanotube/epoxy suspensions. Polymer 54(1):188-198

Pearson RA, Yee AF (1989) Toughening mechanisms in elastomermodified epoxies. J Mater Sci 24:2571-2580
Pei S, Cheng H (2012) The reduction of graphene oxide. Carbon 50(9):3210-3228

Potts JR, Dreyer DR, Bielawski CW, Ruoff RS (2011) Graphenebased polymer nanocomposites. Polymer 52(1):5-25

Tang H, Ehlert GJ, Lin Y, Sodano HA (2012) Highly efficient synthesis of graphene nanocomposites. Nano Lett 12(1):84-90

Tschoppe K, Beckert F, Beckert M, Mülhaupt R (2015) Thermally reduced graphite oxide and mechanochemically functionalized graphene as functional fillers for epoxy nanocomposites. Macromol Mater Eng 300(2):140-152

Wan YJ, Tang LC, Gong LX, Yan D, Li YB, Wu LB et al (2014) Grafting of epoxy chains onto graphene oxide for epoxy composites with improved mechanical and thermal properties. Carbon 69:467-480

Yang H, Shan C, Li F, Zhang Q, Han D, Niu L (2009) Convenient preparation of tunably loaded chemically converted graphene oxide/epoxy resin nanocomposites from graphene oxide sheets through two-phase extraction. J Mater Chem 19(46):8856-8860

Yousefi N, Lin X, Zheng Q, Shen X, Pothnis JR, Jia J et al (2013) Simultaneous in situ reduction, self-alignment and covalent bonding in graphene oxide/epoxy composites. Carbon 59:406-417

Yu A, Ramesh P, Itkis ME, Bekyarova E, Haddon RC (2007) Graphite nanoplatelet-epoxy composite thermal interface materials. J Phys Chem C 111(21):7565-7569

Zaman I, Phan TT, Kuan H, Meng Q, La LTB, Luong L et al (2011) Epoxy/graphene platelets nanocomposites with two levels of interface strength. Polymer 52(7):1603-1611 